\title{
Web-adaptive training system based on cognitive student style
}

Maria A.M. Souto, Mariano Nicolao, Rosa M. Viccari, José P.M. de Oliveira, Regina Verdin, Karine Beschoren, Milton Madeira and

Renata Zanella

PPGC/UFRGS, Instituto de Informática, Porto Alegre, RS, Brazil

UNISINOS, Brazil

CRT Brasil Telecom

Abstract: This paper presents the results of the Project 'Tapejara' - intelligent training system on the internet, a Brazilian Research Council funded project with a partnership of two universities and a Telecom company. This research project uses the students' cognitive learning styles (CLS) to customise course presentation. The CLS is acquired from a sample of telecommunication organisation employees. Individual CLSs are correlated with the students' learning trajectories, allowing automated style identification. Based on the CLS identification, an intelligent agent generates the best-adapted content presentation for each student.

Key words: digital learning environment, learning in a real-life setting, intelligent learning environment, cognitive learning styles, intelligent agents

\section{INTRODUCTION}

The web offers a new stimulus to researchers in the tele-teaching, cognitive psychology and artificial intelligence areas. The new technology facilitates enormously information distribution and communication among teachers and students. From the psychological and pedagogical point of view important challenges remain opened despite the technological advances. Most available web learning systems offer teaching strategies that are a mimetic version of traditional classes. The web's main characteristic, adaptability, is underused and a standard content is offered to each 
individual student. This is a worse situation than teaching in physical classes, as a good teacher adapts the class work to the specific characteristics of each student. Our research focus is the pedagogical coverage of the variety of student's cognitive styles as a referential to adapt and adjust web educational strategies to each specific student (Frasson, 1998; Oliveira, 1998).

Intelligent tutoring systems (ITS) are complex systems that involve several and different kinds of knowledge, such as the content, student's knowledge, and pedagogical knowledge required to adapt the instruction to student's conditions (D'Amico, 1998; Giraffa, 1999; Silveira, 1999). These characteristics differentiate ITS from other knowledge-based systems, where knowledge acquisition on the students' learning style phase happens at an early stage of system use (Frasson, 1997). In contrast, in an intelligent tutoring system, student behaviour analysis and content module generation are performed 'on the fly' for each student and at each stage of the course.

The educational environment modelled in the Tapejara Project Intelligent Systems of Education on the internet (Tapejara, 2001) works with part of these challenges. The intelligence of this system is based on modelling the student's cognitive learning style (CLS) (Riding, 1991; Riding, 1997; Atkinson, 1998). In this context, CLS characterises a pattern of cognitive actions represented by trajectories that can be concretely observed through perceptible performance behaviour that is produced during learning practice from underlying cognitive processes. The study of these trajectories is accomplished through the analysis of the "paths" followed by the students during a free process of learning, a learning phase without the interference of any artificial or human tutor (Madeira, 2001).

\section{COGNITIVE LEARNING STYLES}

Recognising the cognitive styles of learning requires the use of a psychological test to evaluate cognitive processes. This evaluation was based on the 'Ross Test for Cognitive Processes' (Ross, 1997). The Ross test measures and evaluates cognitive processes and abilities related to the specific periods of training which in turn are related to 'Upper Cognitive Activities', mentioned by Bloom (2000).

Upper cognitive processes that the Ross test identifies are: analytical reasoning, deductive reasoning, absent premises, abstract relations, sequential synthesis, questioning strategies, relevant and irrelevant analysis of information, and attributes analysis. We carried out the psychological test on a sample of 231 employees and we established the representative groups of cognitive processes by factorial analysis. The representative groups 
established were (Madeira, 2000): (i) Analogue-Analytical; (ii) ConcreteGeneric; (iii) Deductive-Evaluative; and (iv) Relational-Synthetic.

The Analogue-Analytical CLS student group tends to search new information through the use of patterns that match with other previously learned knowledge. The Concrete-Generic group learns through the linear and sequential browsing of contents, through concrete examples. The Deductive-Evaluation group tends to identify the underlying logical patterns of the contents, making exhaustive analyses of the coherence, validity and veracity of the data. Finally, the Relational-Synthetic CLS student group tends to learn through the reorganisation of the sub-parts of the information supplied in a conceptual and synthetic structure.

\subsection{Analysis of the student learning pattern}

In this stage of the project, the most typical students of each cognitive style are submitted to the non-tutorial instructional module. This module presents didactic material in many alternative styles without any navigational suggestion. The students deal with the module contents through a wide variety of didactic resources such as reading material, examples, exercises, tests, and they are totally free to choose the path accordingly to their preferences. A typical trajectory might be: the student visits a page to execute one exercise then follow another page that contains an example then back to the exercise. In the fourth attempt, the student goes to a reading page on the concept being studied and, in the last attempt of this session, the student accesses another reading page. The psychological and pedagogical analysis of the student's learning trajectories followed in the non-tutorial module begins as soon as the student concludes this module.

To create the students' navigational information a log is generated containing the information on the non-tutorial module navigation. A statistical analysis is performed on the log giving quantitative and qualitative information about a student's behaviour in terms of number of pages accessed, average time of access in each one, and sequence of pages visited.

\subsection{Indexing the generation of learning trajectories}

The students' learning paths can be identified by several indexes that highlight cognitive actions and students' navigation behaviour, recorded during the execution of the non-tutorial module. We consider three main index categories: (i) navigational indexes; (ii) temporal indexes; and (iii) performance indexes. We assume that each CLS group presents a similar behaviour related to the index values derived from the logged data during the instruction. So a learning path pattern exists for each cognitive style. 


\subsection{Correlation analysis between cognitive styles and learning trajectories}

A strong correlation exists between cognitive styles previously identified and learning trajectories covered by the individuals (typical paths of those styles) when executing the instructional non-tutorial module. To verify such correlation we grouped students by quantitative and qualitative results from the log analysis identifying their CLS. The most typical students of a determined CLS was tested to see if it presented similar trajectories and associated indexes.

\subsection{Cognitive style identification}

All the required information was collected to build the psychological and pedagogical knowledge base available. The important data collected were an individual's CLS (from the psychological Ross test), individual learning trajectory and its associated indexes, and the learning trajectories patterns associated with each CLS. These aspects integrated part of the knowledge of the student model represented by a Bayesian belief network (Vanlehn, 1998; Ladeira, 2000; Mayo, 2000).

\section{TRAINING KNOWLEDGE SPACE MODELLING}

Training knowledge space modelling was supported by a remote course authoring workflow methodology (Oliveira, 1998). From this methodology, the course author identifies the main tasks required to plan and develop the contents of the course. The tasks include the definition of the course objectives, the module and topic subdivisions, the bibliography, and the didactic instrument specification such as self-study activities, and assessment instruments.

The different levels of content abstraction represented in each course module are distributed in web pages, resulting in a non-sequential presentation to students. A student is allowed to visit the pages in several and different ways, making it possible for each one to construct a customised trajectory. For each module or topic designed, there is a set of didactic material corresponding to concepts, examples, exercises and review exercises. For the telecommunications course an initial module of TDMA (Time Division Multiple Access) was developed.

The TDMA content was of medium difficulty level. The student begins to navigate in the module and has to accomplish a minimum of $90 \%$ in 
learning performance. This module was developed assuming that the students had as a pre-requisite a working knowledge of multiplex technology. The variety of didactic resources was elaborated to give flexibility and to facilitate student learning. The different forms of presentation were adapted to cognitive styles.

The non-tutorial interface's module of TDMA was developed to prevent student induction in a particular navigation style. The initial module page was composed of two frames. On the left of the upper frame there are three buttons corresponding to didactic resources, presentation forms and final evaluation options. The frame below presents a "layer" with didactic resources offered to the student as concept, examples, exercises and evaluation review. The student has to choose the didactic resource better suited to their personal learning style.

After the student has chosen the preferential didactic resources the system shows alternative forms of presentation of TDMA content. At this time, the student has to choose a preferential presentation form, and then proceed on the navigation through the module contents.

\section{THE EXECUTION MODEL}

An agent, in artificial intelligence, is an autonomous entity working in an environment with other agents or processes. Autonomy means that the agent is independent of constant human interference. An agent is intelligent if it has the ability to select the best-suited actions to achieve some benefit based in the beliefs it has about the world (Wooldridge, 2000). In the Russel definition (1995), an agent is a process that executes the correct action or meaning that the agent selects as a strategy to increase the possibility of success. In our case success is identified by the student capability to acquire the instructional content.

The main goal of the pedagogical agent used in the second phase of use is to assist the student's learning path generation. In this phase, the artificial agent is able to adapt the module contents to the student cognitive style by presenting a standard learning trajectory that matches the CLS. To reach this goal, the pedagogical agent executes four actions: (i) it presents a learning trajectory to the student, based on the CLS; (ii) it records in a log all the student's interactions with the environment; (iii) it analyses students' logged records and updates the data base on the navigational, temporal and performance indexes associated with the student's behaviour; and it adapts the learning trajectory to the student's current state. 


\subsection{Automated learning trajectory generation with an intelligent agent}

The learning trajectory may be modelled as a workflow instance. This modelling approach offers an important improvement to web-learning systems, offering a dynamic content presentation and stimulating the student to develop pro-active behaviour. The workflow approach offers a potentially non-linear content browsing path allowing for a very dynamic content presentation. The student receives a customised workflow instance, tailored for specific content and CLS, allowing at the same time the selection of alternative contents and speed.

The pedagogical agent has the basic function of defining a teaching strategy to guide dynamic content sequence generation. The pedagogical agent based on the student cognitive style selects the specific contents to be presented. The student behaviour evaluation performed by the agent allows the selection of conceptual definitions, explanations, examples, exercises, simulations and other materials in order to adapt the alternative contents to the student's specific characteristics.

This agent follows the workflow course specifications (Oliveira, 1998). The workflow tasks encapsulate the representation of the activities of each course step. The processes involved in a workflow, their relationships and co-ordination are defined, but also the data flow between these processes and the identification of agents to execute the processes is accomplished. In addition, a set of temporal logic rules incorporates a formalism to express reactive computations, usually influenced by events external to the workflow, like exceptions and pre- and post-conditions associated with course execution.

\section{CONCLUSIONS AND FUTURE WORK}

This paper has introduced a methodology to accomplish cognitive learning style modelling. The methodology needed to encompass modelling of the educational environment and had to consider: mapping student modelling; planning and defining the content scope for the courses; planning and developing rich didactic resources; and presentation of adapted content forms to CLS groups.

The results of the project are: the first stage of the CLS modelling methodology establishes the four representative CLS groups to be considered in the educational environment; the modelling of the course module TDMA, and the development of the tools for log generation and 
analysis information from the student trajectory have been used in the nontutorial TDMA teaching module.

We submitted the initial course module TDMA to the most typical student of each CLS group, to investigate the student trajectories of learning, to generate indexes and to establish the correlation analysis between cognitive styles and their learning trajectories; now we are developing a more detailed student model, identifying the qualitative and quantitative variables used in a Bayesian Belief Network for CLS identification.

A technique of conceptual modelling of workflow was developed and training material is being produced (Sizilio, 2000). This technique is intended to specify and to support the workflow implementation of a remote course. In this model, syntactic constructions are introduced to obtain the specification modularisation and workflow parallelism in an efficient way. In addition, transition rules provide a convenient formalism to express reactive computations as they are influenced by external events, generated out of the WMS, as exceptions or non-anticipated pre-conditions of tasks.

We are starting a larger three-year project that will incorporate the prototypical results into a large number of courses in engineering and computer science related to Telecommunication Companies operating in the south of Brazil. This new project is run by a universities and Telcos consortium supported by the Brazilian Research Council.

\section{REFERENCES}

Atkinson, S. (1998) Cognitive style in the context of design and technology work. Educational Psychology, 18, 2, 183-194

Bloom, B. (2000) Taxonomia de Objetivos Educacionais - Domínio Cognitivo. Porto Alegre: Ed. Globo

D'Amico, C.B., Pereira, A.S., Geyer, C.F.R. and Viccari, R.M. (1998) Adapting Teaching Strategies in a Learning Environment on WWW. In Proceedings of the World Conference of the WWW, Internet and Intranet, Orlando, USA.

Frasson, C., Mengelle, T. and Aïmeur, E. (1997) Using pedagogical agents in a multi-strategic intelligent tutoring system. In J.P. Kobe (ed.) Proceedings of the World Conference on Artificial Intelligence in Education.

Frasson, C., Martin, G. and Aïmeur, E. (1998) LANCA: A distance learning architecture based on networked cognitive agents. In Lecture Notes in Computer Science, Vol. 1452, International Conference on Intelligent Tutoring Systems. Berlin: Springer-Verlag

Giraffa, L.M.M., Mora, M. and Viccari, R.M. (1999) Towards a New Computational Model to build a Tutor. In Proceedings of the International Conference on Artificial Intelligence in Education - AIED'99, France, Le Mans.

Ladeira, M. (2000) Diagrama de Influências Múltiplo Secionado. (Ph.D. Thesis in portuguese). 
Madeira, M., Diehl, E., Verdin, R., Wainer, R. and Fraga, T. (2001) Student Cognitive Modeling in Inteligent Tutoring Systems for Distant Learning in the Internet. In XXVIII Inter-American Congress in Psychology, Chile, Santiago del Chile.

Mayo, M. and Mitrovic, A. (2000) Using a probabilistic student model to control problem difficulty. In Proceedings of the International Conference on Intelligent Tutoring Systems. Berlin: Springer-Verlag

Oliveira, J., Palazzo, M. De, Nicolao, M. and Edelweiss, N. (1998) Conceptual Workflow Modelling for Remote Courses, In Proceedings of the XV IFIP World Computer Congress, Teleteaching '98 Distance Learning, Training and Education, Vienna, Austria and Budapest, Hungary.

Riding, R. and Cheema, I. (1991) Cognitive styles: An overview and integration. Educational Psychology, 11, 3 and 4, 193-215

Russel, S.J. and Norvig, P. (1995) Artificial Intelligence - A Modern Approach. Upper Saddle River, New Jersey: Prentice Hall, Inc.

Riding, R. J. (1997). On the nature of cognitive style. Educational Psychology, 17, 2, 29-49

Ross, J.D., Ross, C.M. (1997) Test Ross of Processes Cognitive. São Paulo: Instituto Pieron de Psicologia Aplicada

Silveira, R. and Viccari, R.M. (1999) Eletrotutor - A Distance Learning Multiagents Architecture. In Proceedings of the International Conference on Web - Based Modelling And Simulation,. San Francisco, California, USA.

Sizilio, G.R.M.A. and Edelweiss, N. (2000) Workflow for the Authoring of Long Distance Learning Courses. In Proceedings of the ICECE'2000 - International Conference on Engineering and Computer Education, São Paulo, Brasil.

Description of Project 'Tapejara' (2001). Available at: http://www.inf.ufrgs.br/ tapejara

Vanlehn, K. and Martin, J. (1998) Evaluation of an assessment system based on Bayesian student modelling. International Journal of Artificial Intelligence and Education, 8, 2, 179 221

Wooldridge, M. (2000) Reasoning About Rational Agents. Cambridge, MA: The MIT Press

\section{BIOGRAPHIES}

Maria A. M. Souto, is associated professor at UFRGS, Porto Alegre, Brazil. Regina Verdin, has an M.Sc. in psychology and was a researcher in the Tapejara Project. Karine Beschoren has a bachelor degree in computer science and was a researcher in the Tapejara Project. Renata Zanella has a bachelor degree in computer science and was a researcher in the Tapejara Project. Mariano Nicolao has an M.Sc. in computer science from UFRGS and is associate professor at ULBRA, Canoas, Brazil. Milton Madeira has a docorate in psychology from the Université Catholique de Louvain (UCL), Belgium. During the Tapejara Project he was professor at the UNISINOS University, São Leopoldo, Brazil. Rosa Maria Viccari, has a doctorate in engineering and computer science from the University of Coimbra, Portugal, and is associate professor at UFRGS. José Palazzo M. de Oliveira has a doctorate in computer science, INPG, Grenoble, France, and is a full professor of computer science at UFRGS. He directed the Tapejara Project. 